\title{
A cell-based in vitro assay for testing of immunological integrity of Tetanus toxoid vaccine antigen
}

\author{
Olga Ticha ${ }^{1}$, Dido Klemm ${ }^{1}$, Lukas Moos ${ }^{1}$ and Isabelle Bekeredjian-Ding $\mathbb{D}^{1 凶}$
}

Vaccines containing inactivated toxins confer protection by eliciting a neutralizing antibody response against bacterial toxins such as tetanus and diphtheria. At present, release of tetanus toxoid (TT) and diphtheria toxoid (DT)-containing vaccines relies on in vivo experiments showing the protective vaccine response. The aim of this study was to develop a reliable in vitro assay for $\Pi$ vaccine antigen characterization with the potential of replacing in vivo potency experiments. To this end, we exploited that $\Pi T$ elicits a recall response in vaccinated donors: human peripheral blood mononuclear cells (PBMC) were stimulated with alum-adsorbed $\Pi \pi$ bulk antigen and low concentrations of TLR9 ligand; induction of TT-specific IgG was quantified via ELISpot after 5 days. Proof-ofconcept was obtained using paired samples from donors before and after vaccination; anti-TT IgG was only detected in PBMC collected after booster vaccination; specificity was demonstrated with DT stimulation as control. Notably, when using PBMC from buffy coats, the specific response to $\Pi$ was reproducible in $30 \%$ of cells; responsiveness correlated with higher numbers of switched memory B cells. Consecutive results showed that $\Pi$-specific lgG was also detectable when PBMC were stimulated with DTaP final vaccine product. Thus, the assay provides a viable means to test B-cell differentiation and induction of $\Pi$-specific lgG secretion using bulk antigen and final vaccine. However, prequalification of PBMC is required for reliable performance. Along with physicochemical and immunochemical methods, the functional assay could represent a complementary tool to replace in vivo potency assays in batch release of TT-containing vaccines.

npj Vaccines (2021)6:88; https://doi.org/10.1038/s41541-021-00344-1

\section{INTRODUCTION}

Vaccines confer safety and are the most effective means of protection against infectious disease as demonstrated by the success of vaccines against polio, smallpox, measles, diphtheria, and tetanus among others. Introduction of infant immunization against these pathogens or their disease-provoking toxins has led to an impressive reduction of global disease burden and improved survival of neonates and children worldwide.

Tetanus is a serious illness caused by exposure of a wound to the spores of the bacterium Clostridium tetani, which persist in soil, dust, saliva, or manure. The bacterial toxins affect the nervous system and infection leads to painful muscle spasms and ultimately to death. Tetanus toxoid (TT), e.g., tetanus toxin inactivated with formaldehyde, is the basis for tetanus vaccine formulations, which induce a strong and long-lasting neutralizing antibody response to the toxin $^{1-4}$.

Booster vaccinations are required to acquire long-term protection against tetanus and to maintain immunity over a lifetime. Having established immunity in childhood, adolescents, and adults are recommended to receive booster vaccinations every 10 years at the latest ${ }^{5,6}$. Reflecting this, in Germany, $>75 \%$ of adults have been vaccinated within last 10 years ${ }^{3,7}$.

$\Pi$-induced antibodies represent the correlate of protection for these vaccines, because they neutralize the bacterial toxin, and, thus, prevent disease manifestation. The antibodies are derived from the pool of long-lived plasma cells and memory B cells previously exposed to $\Pi^{8}$. Anti- $\Pi$ lgG serum antibody titers above $0.1 \mathrm{IU} / \mathrm{ml}$ are considered protective ${ }^{6,9-11}$.

The secondary immune response to antigen induces proliferation and differentiation of antigen-specific memory $B$ cells into antibody-secreting cells, which is in vivo accompanied by a transient elevation in serum antibodies. This process has a key role in the neutralization and elimination of pathogens and their virulence factors ${ }^{12-14}$. The currently employed in vivo models for batch release testing of $\Pi$ vaccines are based on inducing in vivo humoral immunity and evaluated either by protection from tetanus toxin challenge or presence of tetanus toxin-specific antibodies ${ }^{15,16}$.

In vivo potency assays used for consistency testing of vaccine batches were established decades ago. The need for replacement and reduction of in vivo methods for quality control of toxoid vaccines is well recognized and enforced by changes in the animal legislation including the European Convention for the Protection of Vertebrate Animals used for Experimental and other Scientific Purposes (ETS No. 123) ${ }^{17}$, Directive of the European parliament and of the council 2010/63/EU on the protection of animals used for scientific purposes ${ }^{18}$ or European Pharmacopoeia chapter (5.2.14) "Substitution of in vivo methods by in vitro methods for the quality control of vaccines"19. Subsequent method developments have focused on quantification of vaccine antigen, absence of toxin, and irreversibility of toxoid, the degree of adsorption of antigen to adjuvant in the final product as well as mass spectrometry-based analyses of protein content to detect inconsistencies in production and susceptibility to degradation ${ }^{20-23}$. However, to date, none of these methods can be used for potency testing of $\Pi$ vaccines, which is classically associated with functional testing. In the present study, we describe a new assay that mimics the process of $\Pi$-induced specific antibody induction in vitro.

Although secretion of antibodies derived from activated plasmablasts can be quantified by seeding them on ELISpot membranes directly after isolation ${ }^{24-26}$, antigen-specific memory $B$ cells need to be stimulated to undergo differentiation to antibody-

${ }^{1}$ Division of Microbiology, Paul-Ehrlich-Institut, Langen, Germany. ${ }^{凶}$ email: isabelle.bekeredjian-ding@pei.de 
secreting cells (ASC). Notably, a variety of protocols developed for detection and enumeration of vaccine and infection-induced antigen-specific memory B cells exist. They are usually based on 3-10-day cultures with addition of polyclonal stimuli, e.g., R848, CpG, pokeweed mitogen, Staphylococcus aureus Cowan strain I, CD40 ligand or anti-CD40 antibody, in combination with differentiation-supporting cytokines such as BAFF, IL-2, IL-6, and IL-10 12,24,27,28. In contrast to previous approaches, the assay developed in this study avoids unspecific, polyclonal B-cell stimulation but makes use of the co-stimulatory potential of TLR9 ligand CpG to support antigen-driven terminal differentiation of memory B cells $\mathrm{s}^{29,30}$.

Here, we present original data demonstrating that eliciting a recall response via dual stimulation with $B$-cell receptor $(B C R)$ antigen and TLR9 ligand can be applied to confirm the presence and test the functional integrity of vaccine antigen in $\Pi$ containing vaccine batches.

\section{RESULTS}

\section{Proof-of-concept: stimulation of TT-specific IgG-secreting B} cells in PBMC collected before and after vaccination

To enable in vitro testing of the functional integrity of $\Pi$ vaccine antigen, we established a human PBMC assay based on dual stimulation of $B$ cells with $T$ bulk antigen and a low concentration of TLR9 ligand CpG ODN 2006. The assay principle is summarized in Fig. 1a. In brief, a TT-specific B-cell response was triggered with $\Pi$, co-stimulation with B-cell-active CpG was included to support differentiation of B cells into ASC. TT-specific and total lgG were quantified via ELISPOT.

PBMC from healthy volunteers were obtained before and after vaccination with a booster dose of DTaP vaccine. Cells obtained from these paired samples were stimulated with CpG in the presence and absence of $\mathrm{AlPO}_{4}$-adsorbed $\Pi$ for 5 days. Stimulation of PBMC from donors before vaccination did not result in the generation of anti-TT lgG-secreting cells (Fig. 1b, c), although release of IgG was intact in controls (Supplementary Fig. 1a). By contrast, anti-TT lgG-secreting cells were detected in the corresponding samples of 8 out of 11 donors post vaccination (Fig. 1b, c; see Supplementary Fig. 1b for total IgG and single donor values). The specificity of the $\Pi T$ response was controlled by stimulation with $\mathrm{AlPO}_{4}$-adsorbed diphtheria toxoid (DT). The results confirmed the specificity of $\Pi$-specific antibody detection. However, cells from two freshly vaccinated donors with high levels of anti-TT IgG enzymatic reactivity also displayed a positive despite lower response to DT, while all other samples (before and after vaccination) showed a negative $\Pi$-specific lgG response (Fig. $1 \mathrm{~b}$ and Supplementary Fig. 1).

\section{Frequency of TT-specific B cells and induction of TT-specific IgG-secreting cells in PBMC from buffy coats}

Since obtaining the samples from freshly vaccinated donors is logistically challenging, we evaluated the feasibility of use of PBMC from buffy coats. In a preliminary study with 26 donors, we confirmed that $\Pi$-specific switched memory lgG-positive B cells are detectable in buffy coat-derived PBMC and are not subject to relevant variance (Supplementary Fig. 2). TT-specific B cells a)

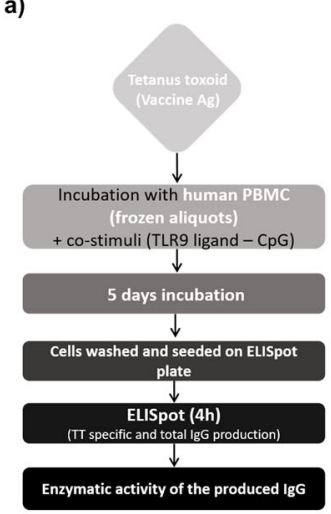

b)

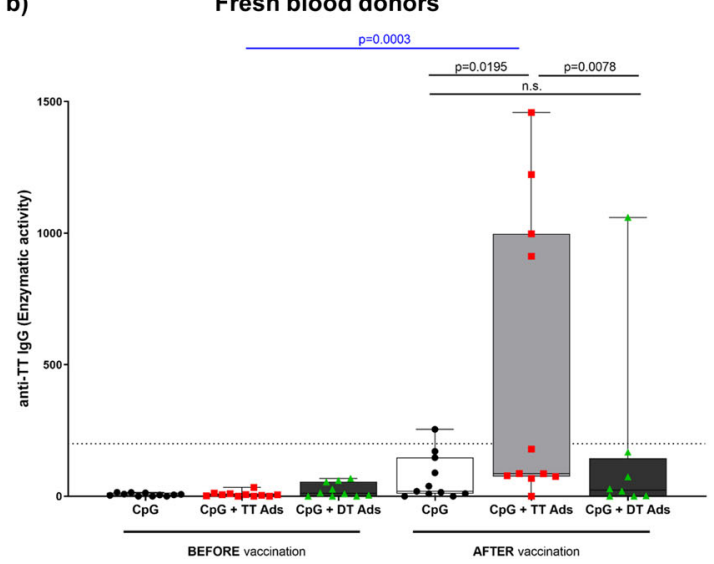

d)

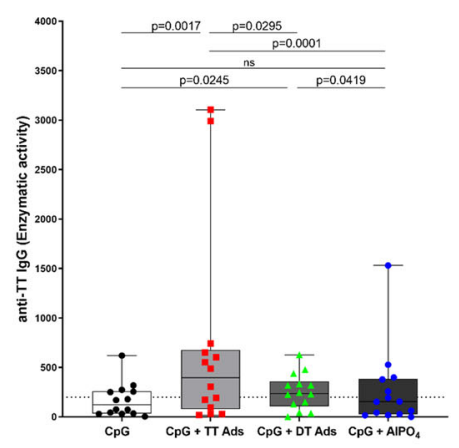

c)

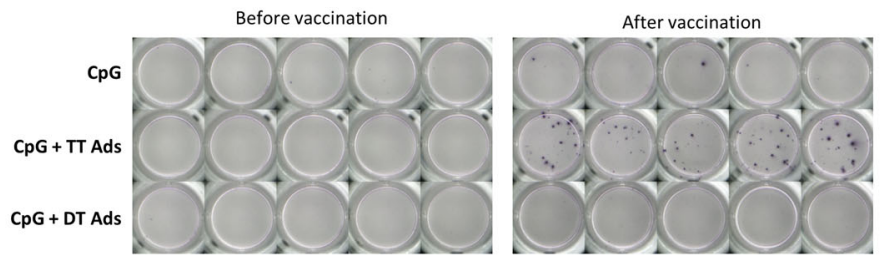

Fig. 1 Proof-of-concept for a cell-based assay providing a functional readout for TT. a Assay layout. b Anti-TT IgG-specific enzymatic activity response in an assay performed with PBMC obtained from 11 donors before and after DTaP booster vaccination. Paired samples from individual donors before and after vaccination were tested in parallel. The graph summarizes the results from $n=3$ independent experiments performed with 6, 4, and 1 donors, respectively. Bar graphs represents the interquartile range with median and whiskers depicting maximal and minimal values, each dot represents mean of enzymatic activity of a single donor. Data were analyzed using two-tailed Wilcoxon matched-pairs signed rank test (black lines and symbols), Mann-Whitney test (blue line and symbols). c ELISpot wells coated with TT for detection of anti-TT IgG of one representative donor showed (Donor \#2). d Anti-TT IgG enzymatic activity of 14 buffy coat donors in response to CpG + adsorbed TT compared to the response to CpG + adsorbed DT or to CpG + aluminum adjuvant. Bar graphs represent the interquartile range with median and whiskers depicting maximal and minimal value, each dot represents mean of enzymatic activity of a single donor. Combined values from 14 buffy coats ( $n=4$ independent experiments) donors with statistical evaluation (Wilcoxon matchedpairs rank test). $P$ values are depicted in the respective graphs, ns non-significant. The dotted line shows anti-TT IgG enzymatic activity of 200 , the threshold of reactivity. 
a)

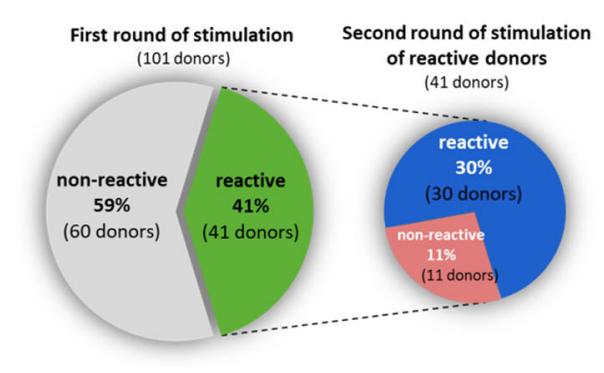

c)

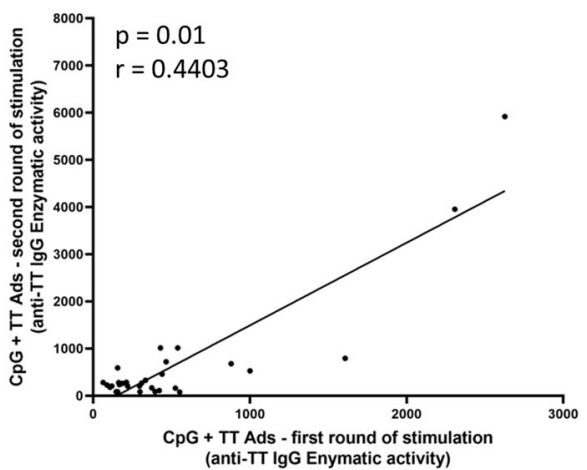

b)

Buffy coats

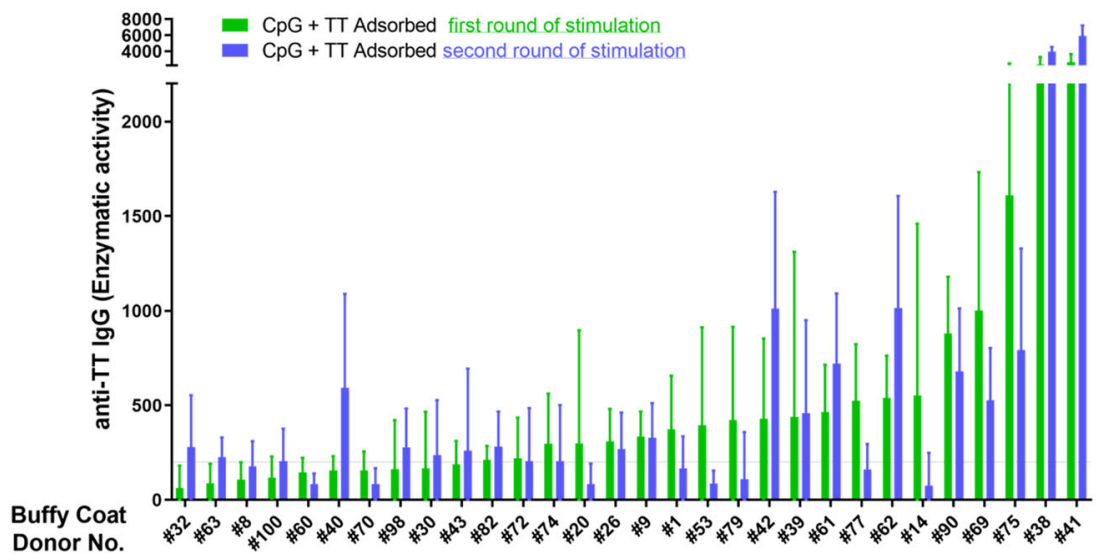

Fig. 2 Variability of TT responses among buffy coat donors. a Overview of the results from two consecutive rounds of experiments in 101 and 41 donors, respectively. b Means of enzymatic activity of anti-TT IgG produced in response to CpG + TT from 30 donors in first and second round of experiment (Donors are arranged according increasing mean value of anti-TT lgG enzymatic activity in a first round of experiments). Bar graphs represent mean (+ standard deviation) of all technical replicates (four and eight technical replicates per donor cell sample in first and second experiment, respectively). First round of experiments: $n=101$ independent donors and $n=11$ independent experiments. Second round of experiments: $n=41$ independent donors and $n=9$ independent experiments. c Spearman correlation of means of enzymatic activity anti-TT IgG response to $\mathrm{CpG}+\mathrm{TT}$ from first and second round of experiment (30 reactive donors).

accounted for $0.13 \pm$ SD $0.1521 \%$ of lgG + memory B cells, which corresponds to $0.012 \%$ of total peripheral B cells.

We subsequently performed the assay with buffy coat-derived PBMC. Since the TT bulk antigen used in the experiments was adsorbed to alum adjuvant, we included controls with alum adjuvant alone. Thus, PBMC were stimulated with $\mathrm{CpG}$ and either $\Pi$ or DT adsorbed to $\mathrm{AlPO}_{4}$ or $\mathrm{AIPO}_{4}$ alone (Fig. $1 \mathrm{~d}$ and Supplementary Fig. 3). The results showed that exposure to alum-adsorbed $\Pi$-induced differentiation of anti- $T$ IgG-secreting $B$ cells. By contrast, aluminum phosphate alone or in combination with DT did not induce B cells producing anti-TT lgG, thus confirming the applicability of buffy coat-derived PBMC and the specificity of the assay.

\section{Stimulation with TT distinguishes responsive and non- responsive PBMC donors}

To study the robustness and reliability of the assay, we carried out experiments with PBMC of 101 buffy coat donors. Initial stimulation was carried out with four technical replicates in each condition. As expected, the results showed significant donor variability. After stimulation with $\mathrm{AlPO}_{4}$-adsorbed $\mathrm{TT}$ in combination with CpG anti-TT lgG-producing cells were increased in 41 donors when compared to CpG only (Supplementary Fig. 4a). However, 60 out of 101 donor cells were categorized as non- responsive because either enzymatic activity of anti-T IgG remained below the baseline (i.e., 200), or anti-TT IgG levels after stimulation with $\mathrm{CpG}$ only superseded those of $\Pi+\mathrm{CpG}$.

To evaluate reproducibility of results, we repeated the experiments with the PBMC from responsive donors. In the second round, under the same conditions, we used eight technical replicates per condition to increase the cell volume tested (Supplementary Fig. 4b). Out of the 41 re-evaluated PBMC samples we confirmed reactivity to $\mathrm{AlPO}_{4}$-adsorbed $\Pi \mathrm{T}$ in only 30 donors, corresponding to $30 \%$ of the $n=101$ tested buffy coats (Fig. 2a). The mean enzymatic activities obtained with the responsive cells in both the first and second rounds are depicted in Fig. 2b. Compared with high variability among donors, the intraassay variability at individual donor level was negligible, e.g., enzymatic activity levels display a statistically significant correlation $(p=0.01)$ (Fig. 2c). Slight differences in enzymatic activity levels reflect the expected inter-experimental variation. The high standard deviations on individual donor level depicted in Supplementary Fig. 4 result from variation among the technical replicates, accounting for the differences in the number of $\Pi$ specific B cells in each well (e.g., per 2 Mio of PBMC). For future developments, this could be avoided by pooling of technical replicates before analysis. However, the variation shown manifests the need for acquisition of data from high PBMC numbers. 


\section{Switched memory B cells counts correlate with TT responsiveness}

Since prequalification of PBMC might represent a suitable strategy to improve robustness of the assay, we characterized PBMC in regard to B-cell counts and proportional representation of B-cell subpopulations (Table 1) and correlated the findings with reactivity of the PBMC. Analysis of the eleven donors that were reactive only once revealed that these $P B M C$ were characterized by low counts of switched memory B cells (CD19+lgM-CD27+) per $10^{6}$ PBMC when compared with reactive donors (Fig. 3a), which could explain the variability of the response. Comparison of reactive and non-reactive donors revealed that the switched memory B-cell counts were significantly higher in donors with confirmed reactivity (Fig. 3a).

Since the frequency of $\Pi$-specific memory $B$ cells was found to be very consistent in relation to the lgG-positive memory $B$ cells subpopulation (Supplementary Fig. 2), the experimental use of higher total memory $B$ cells increased frequencies of TT-specific switched memory $B$ cells and $\Pi$ reactivity. This was reflected by a

\begin{tabular}{|lll|}
\hline \multicolumn{2}{|l}{ Table 1. Buffy coat donors' characteristics-data from 101 buffy coats. } \\
\hline Parameter & Median $( \pm$ SD) & Min-max \\
\hline Lymphocytes (\%) & $80( \pm 6.1)$ & $54-92$ \\
B lymphocytes (\%) & $8( \pm 3.1)$ & $2-18$ \\
Lymphocytes/1 Mio PBMC & 800,000 & $544,000-921,000$ \\
& $( \pm 60,975)$ & \\
B-cell count/1 Mio PBMC & 60,975 & $17,250-127,565$ \\
& $( \pm 24,791)$ & \\
Naive B cells (\%) & $63( \pm 15.4)$ & $20-91$ \\
IgM memory B cells (\%) & $19( \pm 11.1)$ & $3-57$ \\
Isotype switched memory B & $16( \pm 8.9)$ & $9-80$ \\
cells (\%) & & \\
Isotype switched memory B cells & $9094( \pm 7877)$ & $2283-62,157$ \\
count/1 Mio PBMC & $1.5( \pm 1.5)$ & $0.1-7.3$ \\
Anti-TT IgG (IU/ml) &
\end{tabular}

strong correlation $(p<0.0001)$ of $T$-specific memory B-cell counts with counts of switched memory B cells per 1 Mio PBMC (Supplementary Fig. 5a). TT-specific memory B-cell counts were further increased in reactive PBMC (Fig. $3 b$ ). There was further a positive correlation of initial counts of switched memory B cells ( $p$ $=0.003)$ and TT-specific memory B cells $(p<0.0001)$ with the enzymatic activity of anti-TT IgG (Supplementary Fig. 5b, c).

We subsequently analyzed the correlation of anti-TT IgG levels in plasma with functional reactivity in the TT-specific B-cell assay. Despite correlation of anti- $\Pi$ IgG levels with $\Pi$-specific memory $B$ cells (Supplementary Fig. 5d), statistical analysis showed no difference in anti-TT lgG levels from non-reactive and reactive donors (Fig. 3c). Anti-TT lgG in plasma was thus not predictive for reactivity. However, induction of anti-TT-IgG-secreting cells upon polyclonal stimulation of PBMC with B-cell-active TLR9 ligand CpG alone revealed that reactive donors reach significantly higher values (Fig. 3d), which is well in line with a higher number of $\Pi$ specific memory B cells (Fig. 3b).

Finally, we asked whether the age of the buffy coat donors would need to be taken into account. Although a trend towards higher age in the responsive donors was observed, no statistical difference in regard to age distribution was found in the responsive and non-responsive groups (Fig. 3e).

\section{Alum does not alter specificity but influences secretion of TT- specific IgG}

Aluminum salts commonly used for $\Pi$ adsorption such as aluminum hydroxide or phosphate enhance the immunogenicity of the vaccine antigens. We stimulated the cells with CpG in combination with adsorbed and non-adsorbed $\Pi$ (Fig. 4a). The results showed that production of anti-T IgG produced was comparable and the presence of aluminum phosphate did not alter the response level, while on individual donor level the means of enzymatic activities in both conditions correlated well $(p=0.03)$ (Fig. 4b).

Since it has repeatedly been claimed that alum is cell-toxic, we asked whether increasing amounts of antigen and adsorbed adjuvant would affect the results. The results showed that enzymatic activities derived from anti-TT IgG-secreting $B$ cells a)

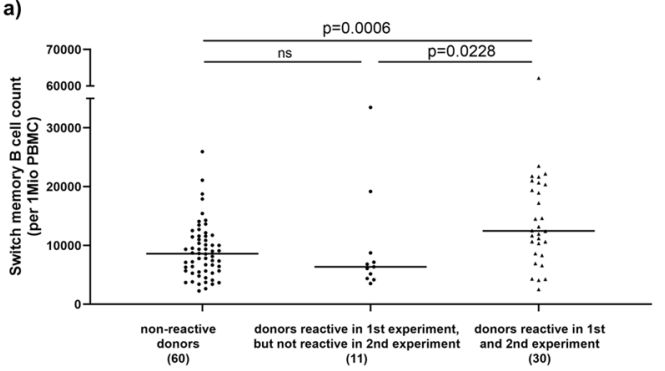

d)

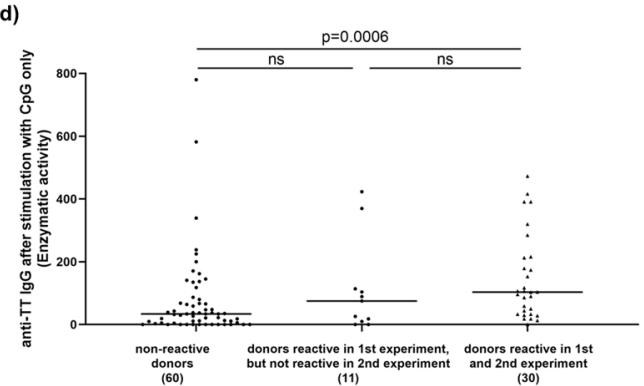

b)

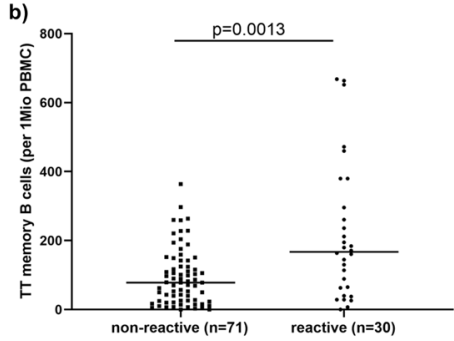

e)

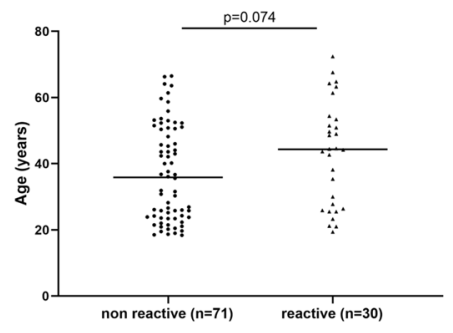

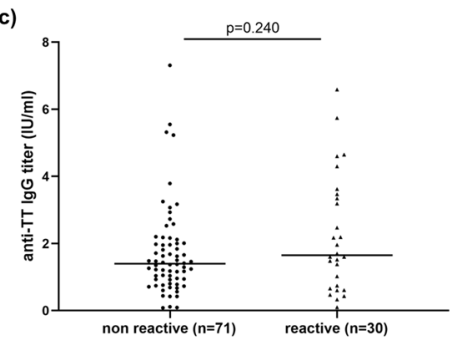

Fig. 3 Definition of prequalification criteria for PBMC use. Phenotypical and functional comparison of responsive and non-reactive donors from 101 buffy coat donors. a Switched memory B-cell count $/ 10^{6}$ PBMC, b TT-specific switched memory B cells $/ 10^{6}$ PBMC, c levels of anti-TT IgG in plasma, $\mathbf{d}$ enzymatic activity of anti-TT IgG response to CpG only, and e age of non-responders and responsive buffy coat donors. Data were analyzed using Mann-Whitney test. $P$ values are depicted in the respective graphs, ns non-significant. 
a)

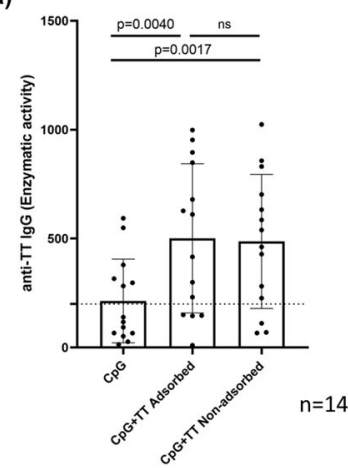

d)

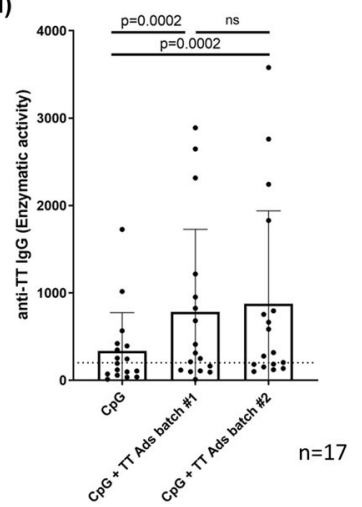

b)

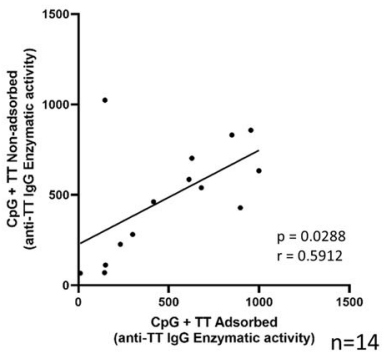

e)

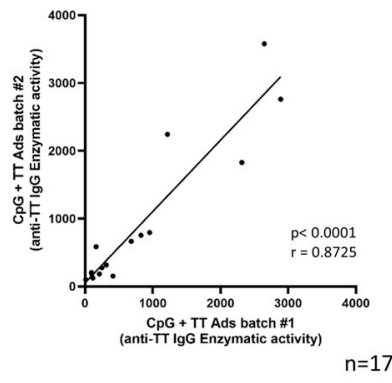

c)

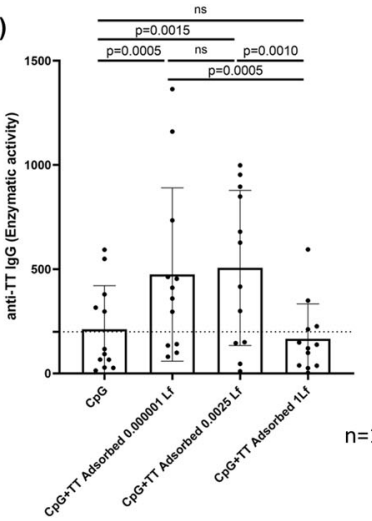

f)

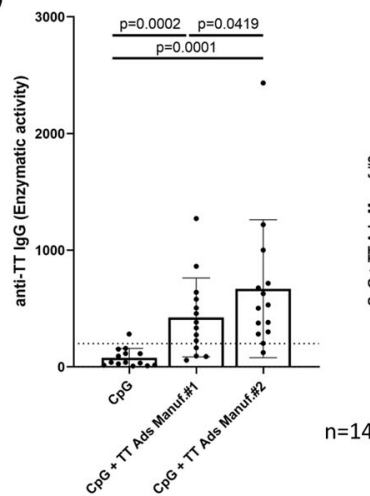

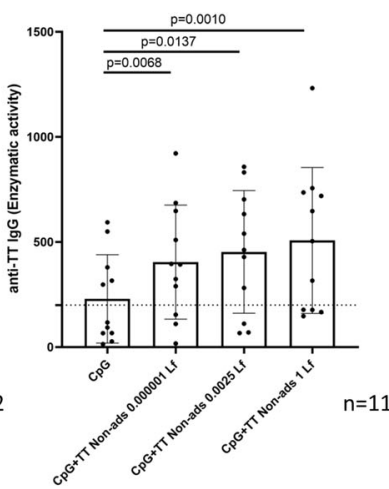

g)

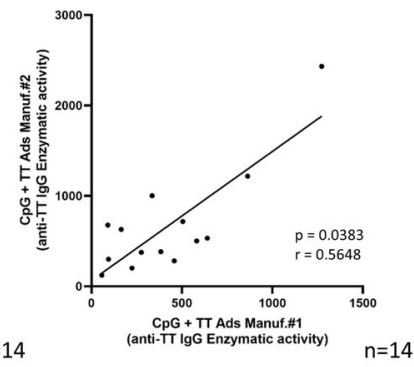

Fig. 4 Influence of adjuvant and batch-dependency of the response. Impact of TT adsorption on alum and antigen concentration on anti-TT IgG production in buffy coat donors. a Comparison of response to TT adsorbed vs non-adsorbed $(0.0025 \mathrm{Lf} / \mathrm{ml})(14 \mathrm{donors} ; n=7 \mathrm{independent}$ experiments), $\mathbf{b}$ correlation of the enzymatic activity of anti-TT IgG in response to TT adsorbed and non-adsorbed ( $0.0025 \mathrm{Lf} / \mathrm{ml})$ of individual donors (each represented as a single dot), $\mathbf{c}$ titration of TT adsorbed (left panel) ( 12 donors; $n=7$ independent experiments) and titration of TT non-adsorbed (right panel) (11 donors; $n=7$ independent experiments). $\mathbf{d}$ Comparison of the enzymatic activity of anti-TT IgG in response to two different batches from the same manufacturer (17 donors; $n=4$ independent experiments) and e correlation of the means of enzymatic activity of anti-TT IgG of the individual donors in response to the batch \#1 and \#2 (each donor represented as a single dot) ( $n=4$ independent experiments). $f$ Comparison of the enzymatic activity of anti-TT IgG in response to adsorbed TT from two different manufacturers (14 donors; $n=3$ independent experiments) and $\mathbf{g}$ correlation of the means of enzymatic activity of anti-TT IgG of the individual donors in response to the TT adsorbed from Manufacturer \#1 and \#2 (each represented as a single dot). Bar graphs represent mean ( \pm standard deviation) of the enzymatic activity means of all donors. The dotted line shows anti-TT IgG enzymatic activity of 200, the threshold of reactivity. Data were analyzed using Wilcoxon matched-pairs signed rank test and Spearman correlation. $P$ values are depicted in the respective graphs, ns nonsignificant.

produced in response to $0.000001 \mathrm{Lf} / \mathrm{ml}$ or $0.0025 \mathrm{Lf} / \mathrm{ml} \mathrm{TT}$ were comparable and independent of the adsorption with alum (Fig. 4c). However, $1 \mathrm{Lf} / \mathrm{ml}$ of adsorbed $\Pi \mathrm{T}$ leads to a statistically significant reduction in enzymatic activity, which was not seen with non-adsorbed $\pi$ bulk antigen (Fig. 4c).

\section{TT batches induce comparable amounts of TT-specific IgG}

Since the objective of the study was to develop an assay that could be used for consistency testing in quality control and batch release of bulk antigen and vaccine, we evaluated the induction of $\Pi$-specific ASC in response to two different batches of the alum-adsorbed $\Pi$ bulk antigen from the same manufacturer (Fig. $4 d$ ). Levels of anti-TT IgG enzymatic activity were comparable, which was further supported by a very strong correlation $(p<$ 0.0001 ) of anti-TT IgG enzymatic activity on an individual donor level (Fig. 4e).

\section{Quantitative TT response differs depending on the manufacturer}

To further understand the precision of the assay, we studied the anti-T IgG responses to bulk antigen from different manufacturers. The antigen preparations differed in the adjuvant used for adsorption, e.g., aluminum phosphate versus aluminum hydroxide. The results showed that anti- $T$ IgG secretion was elicited by both $\Pi$ preparations, even though the reaction to that provided by manufacturer \#2 was consistently higher than that of manufacturer \#1 (Fig. 4f). Notably, $\Pi$ T adsorbed from manufacturer \#2 contained 10 times higher concentration of aluminum $\mathrm{Al}^{3+}$. Importantly, anti- $\Pi$ IgG responses of adsorbed $\Pi$ from two manufacturers using different alum adjuvants demonstrate statistically significant correlation on individual donor level ( $p=$ 0.04) (Fig. 4g).

\section{Heat alteration of TT does not change levels of anti-TT IgG}

Next, we tested whether the assay detects heat alteration of $\Pi$. To this end, we used two different heat treatment protocols: $\Pi$ was either incubated at $37^{\circ} \mathrm{C}$ for 4 weeks or at $45^{\circ} \mathrm{C}$ for 1 week. The results shown in Fig. 5 and Supplementary Fig. 6 revealed no statistically significant change in enzymatic activity levels. However, heat treatment at $45^{\circ} \mathrm{C}$ increased variability of results, which was reflected by a higher standard deviation, an increased $p$ value, a decreased correlation coefficient and increased scattering of single values along the trend line when compared with the lessrigorous protocol at $37^{\circ} \mathrm{C}$. 


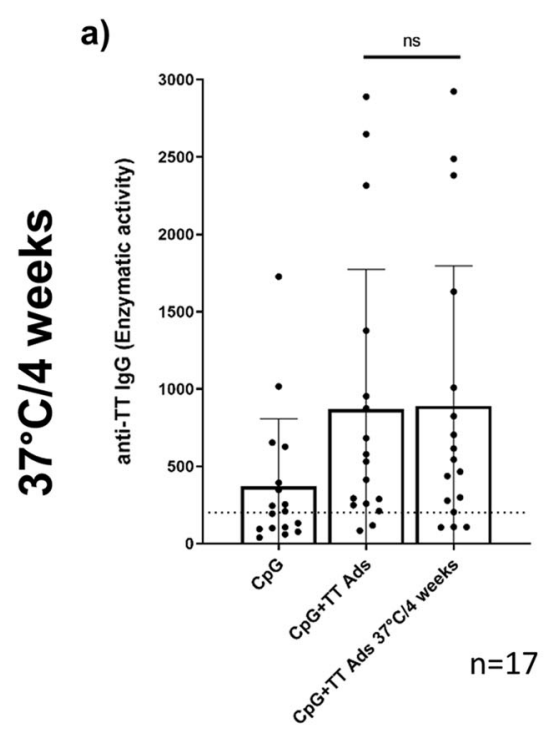

c)

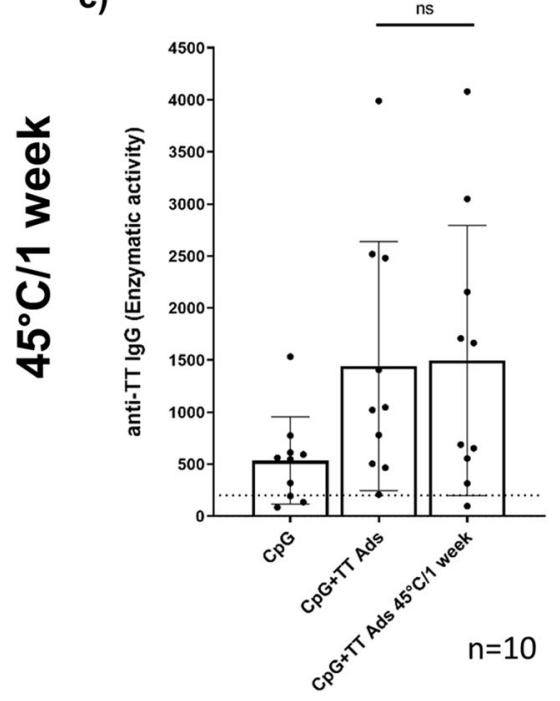

b)

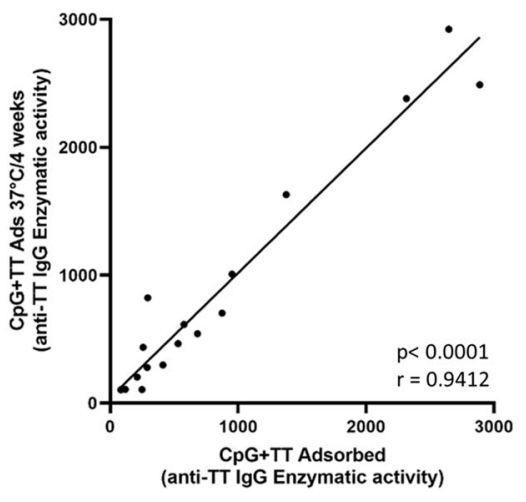

$n=17$

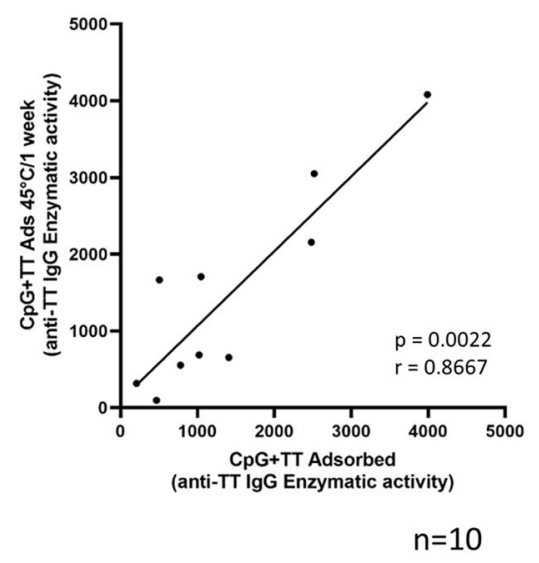

Fig. 5 Influence of heat alteration of TT. Anti-TT IgG enzymatic activity of buffy coat donors in response to heat alternated adsorbed TT $(0.0025 \mathrm{Lf} / \mathrm{ml}): \mathbf{a}$, b TT kept at 4 weeks at $37^{\circ} \mathrm{C}$ (17 donors; $n=5$ independent experiments) and $\mathbf{c}$, $\mathbf{d}$ TT kept one week at $45^{\circ} \mathrm{C}(10$ donors; $n=$ 2 independent experiments). $\mathbf{a}, \mathbf{c}$ comparison of response to not-altered vs altered adsorbed TT. $\mathbf{b}$, $\mathbf{d}$ correlation of the enzymatic activity of anti-TT IgG in response to not-altered vs altered adsorbed TT of individual donors (each represented as a single dot). Bar graphs represent mean ( \pm standard deviation) of the enzymatic activity means of all donors. The dotted line shows anti-TT IgG enzymatic activity of 200 , the threshold of reactivity. Data were analyzed using Wilcoxon matched-pairs signed rank test and Spearman correlation. $P$ values are depicted in the respective graphs, ns non-significant.

\section{Induction of TT-specific IgG secretion by treatment with final vaccine product}

The ultimate goal of this assay development is to test final vaccine product batches. Thus, we tested the response of reactive donor PBMC to final DTaP vaccine product. A drop-out DaP sample lacking $\Pi$ was used as a control. The results obtained in these experiments showed a $\Pi$-specific response that was absent when PBMC were stimulated with the drop-out sample (Fig. 6 and Supplementary Fig. 7). These findings indicated that the assay is compatible with use of final vaccine product.

\section{DISCUSSION}

It is well known that memory B cells enable rapid responses upon re-encounter with a known pathogen ${ }^{31}$. These responses require expansion and subsequent differentiation of antigen-specific B cells into antibody-producing cells. Use of ELISpot is well established for detection of antigen-specific memory B cells and determining the frequency of pathogen and vaccine-specific $B$ cells $^{25,27,28,32-35}$. However, the published protocols focus on the enumeration of antigen-specific $B$ cells and are therefore based on polyclonal stimulation (Bernasconi et al. 2002; Crotty et al. 2004; Weiss et al. 2012; Jahnmatz et al. 2013), which was used for characterization of PBMC in Fig. 3d. By contrast, in this study, we were interested in selective induction of terminal differentiation of antigen-specific B cells to test the quality of the vaccine antigen. Our protocol, thus, builds on the existing pool of $\Pi$-specific memory B cells. Although a TLR ligand was used to facilitate proliferation, survival, and differentiation of $\Pi T$-specific $B$ cells, the low concentration of CpG ODN used avoided unselective expansion and differentiation of B cells in the absence of a BCR stimulus (i.e., TT) (Fig. 1b-d and Supplementary Fig. 1 and 3). This permitted the establishment of an assay that confirms functional integrity. 


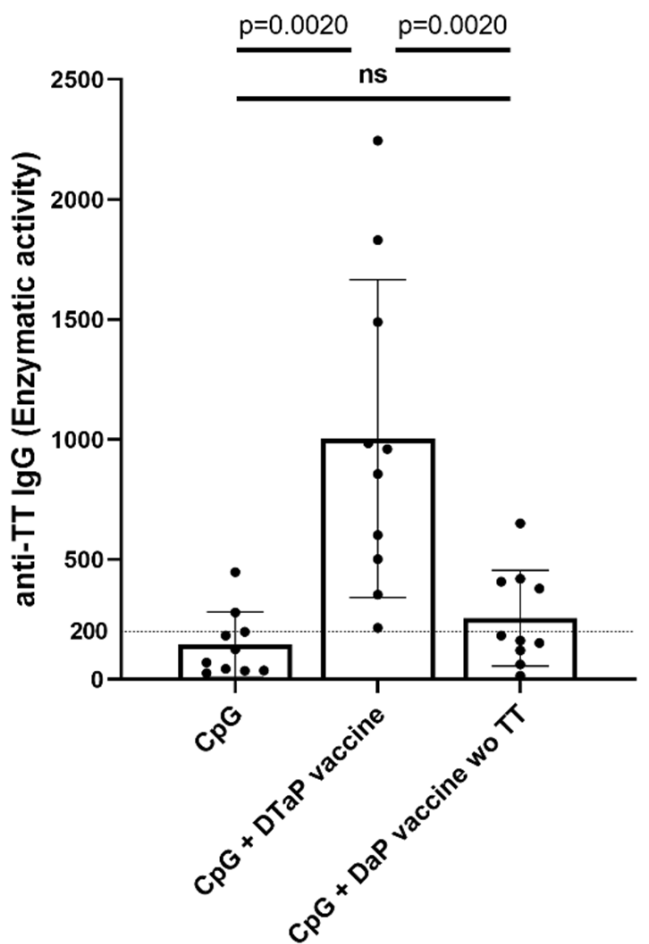

Fig. 6 Detection of TT responses with final vaccine product. AntiTT IgG enzymatic activity in response to CpG + DTaP and DaP vaccine without TT in buffy coat donors. Combined values of enzymatic activity from 10 buffy coats donors with statistical evaluation (Wilcoxon matched-pairs rank test) $(n=4$ independent experiments). Bar graphs represent mean ( \pm standard deviation) of the enzymatic activity means of all donors. The dotted line shows anti-TT IgG enzymatic activity of 200 , the threshold of reactivity. $P$ values are depicted in the respective graphs, ns non-significant.

In this study, assay development was facilitated by the fact that the frequency of TT-specific B cells in peripheral blood is high when compared with other antigens. According to the literature, it can reach up to $0.14 \%$ of IgG-producing memory B cells, which approximately represent $0.02 \%$ of all circulating $B$ cells ${ }^{36-39}$. This percentage corresponded well with the number of $\Pi$-specific lgGpositive B cells we determined in buffy coat-derived PBMC. Using flow cytometric analysis we estimated the frequency of $\operatorname{lgG}$ memory B cells at $0.13 \%$, which corresponds to $0.012 \%$ of total peripheral blood B cells (Supplementary Fig. 2).

According to the literature, $\Pi$-specific plasma cell counts peak around day 7 after booster vaccination ${ }^{37,40}$, whereas the anti-TT memory B-cell count reaches its maximum in peripheral blood 1-2 weeks after immunization ${ }^{24,37}$. Here, proof-of-concept was demonstrated in experiments using paired samples from healthy donors before and after booster DTaP vaccination. The results showed that immunization increased $\Pi$-specific IgG-secreting cells (Fig. 1b). Notably, the response to $\Pi$ was not detectable before booster immunization. In light of previous vaccination dating back between 5 and 26 years, this was well in line with the gradual drop in memory B-cell counts in peripheral blood described subsequent to vaccination ${ }^{24,37}$ and highlighted the requirement for booster immunization to pass the detection threshold of the assay. However, similarly to the results obtained in buffy coat-derived PBMC where $30 \%$ of donors were reproducibly responsive, some donors (\# 4, 6, and 8; e.g., 3 of 11 donors) were unresponsive. The reasons for this finding remain to be clarified: no difference was identified based on years elapsed from previous vaccination, number of days post vaccination, switched memory B-cell counts or levels of anti-TT antibodies in plasma. Furthermore, we can only speculate whether unspecific responses to DT reflect elevated activation of antibody-secreting cells after vaccination.

Since the assay builds on a secondary immune response, it was further not surprising that PBMC from buffy coats displayed a broadly variable range of reactivity (Supplementary Fig. 4). Nevertheless, in this study, we took advantage of the high coverage with $\Pi$ vaccination in the German population. Here, $\sim 70-75 \%$ of adults were vaccinated in the last 10 years ${ }^{3,7}$. Although we presumed that blood donors were likely to have received $\Pi$ vaccination in the past, information on the individual history of vaccination and the time elapsed from the last (re) vaccination was not available. We reduced the impact of this variability on the performance of our assay by two measures: (i) to increase sensitivity we performed experiments using a high number of technical replicates with the aim of increasing the total amount of B cells analyzed per sample (Fig. 1b, Supplementary Fig. 1, Supplementary Fig. 3), thus accounting for samples with low frequency of $\Pi$ T-specific memory B cells; (ii) we further sought to identify criteria predictive of donor reactivity and subsequently developed prequalification protocols to enable reliable routine use of cryopreserved PBMC.

When we studied the relationship between donor reactivity and memory B-cell counts, we observed that reactive donor cells on average contained higher counts of switched memory B cells than donors whose cells were not reactive or with reactivity not reproducible upon repetition (Fig. 3a). This observation implied that a higher proportion of memory $B$ cells also results in higher numbers of $\Pi$-specific memory $B$ cells. Taking into account that the use of technical replicates increased sensitivity of the assay, we concluded that a minimal representation of memory B cells could serve as a prequalification criterion for inclusion of donor PBMC into the biobank. Indeed, a threshold of $>10.000$ memory B cells per $10^{6}$ PBMC would have increased the proportion of reactive donors: 22 of 46 (48\%) PBMC samples fulfilling this criterion would have been repeatedly reactive (Fig. 7). Most importantly, all donor cells reactive in the first but not in the second round of stimulation would have been excluded by application of this criterion.

Precise assessment of the number of $\Pi$-specific memory $B$ cells could represent an alternative parameter for prequalification. The enumeration of anti-T IgG-secreting cells following polyclonal Bcell stimulation was discarded because it provided no advantage compared with flow cytometric quantification of switched memory B cells and requires more time and cost. Notably, this criterion did not reliably distinguish reactive from non-reactive donors (Fig. 3b) we favored total switched memory B-cell counts. Furthermore, direct quantification of this rare subpopulation by flow cytometry requires extensive event collection, ideally performed with enriched B cells, which would be accompanied by significant cell loss and was therefore, also abandoned.

Assuming that anti-TT IgG levels might correlate with PBMC reactivity, we quantified anti-TT IgG in plasma obtained from buffy coats (Fig. 3c). In agreement with previous reports, the numbers of $\Pi$-specific memory B cells did not correlate with anti-TT lgG levels ${ }^{36,41}$ nor was there any statistically significant difference between non-responders and reactive donor cells.

Since BCR affinity to antigen increases with the number of somatic hypermutations introduced by repeated encounter of the antigen $^{42-44}$, we hypothesized that affinity maturation of the TTspecific BCR repertoire, in particular avidity to $\Pi$, could account for the missing correlation of $\Pi$-specific memory B-cell numbers with reactivity. This premise was well in line with a trend towards a higher age in reactive donors when compared with nonresponders (Fig. 3e). However, follow-up studies will need to explore the relevance and the feasibility for preselection of reactive donors. Based on the observations made, we propose a two-step approach for prequalification of donor cells: (1) initial selection of PBMC based on memory B-cell counts can avoid 


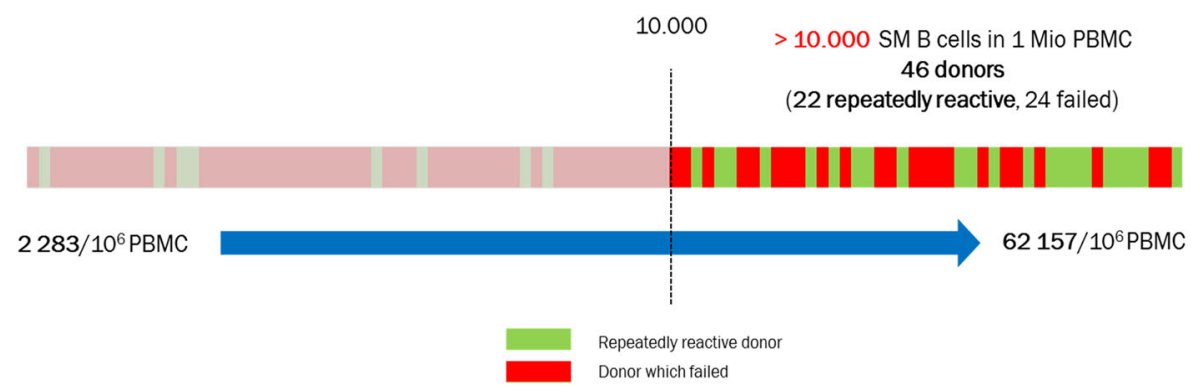

Fig. 7 Threshold for reactivity of donors. A threshold of $>10,000$ memory B cells per $10^{6}$ PBMC can increase the proportion of reactive donors. This criterion would have reduced the number of donors to be subjected to functional evaluation to 46 of 101 donors; 22 ( $48 \%$ ) of these PBMC samples would have been repeatedly reactive and the proportion of non-responders in pre-testing could have been reduced from 70 to $52 \%$.

unnecessary testing of non-reactive donors; and (2) the remaining samples need to be functionally tested for reactivity to $\pi$ stimulation. In addition, we propose that the donor cell qualification criteria could be amended by a minimal requirement for reactivity in two out of six wells. Optionally, the assay performance could be improved by increasing the number of technical replicates (e.g., 12). This approach represents an important means for reduction of variability, standardization and insurance of robustness, and reproducibility of the B-cell assay.

Since the objective of our study was to develop an assay that would be suitable for vaccine antigen characterization and quality control of $\Pi$ vaccines, we explored the limits of the methodological approach with a variety of different materials provided by vaccine manufacturers. The results confirmed that the assay is specific for $\Pi \mathrm{T}$ in a wide range of the antigen concentrations (Fig. 4c) $(0.000001 \mathrm{Lf} / \mathrm{ml}$ to $0.0025 \mathrm{Lf} / \mathrm{ml})$ with no interference attributable to the presence of alum adjuvant in absorbed $\Pi \pi$ up to $0.0025 \mathrm{Lf} / \mathrm{ml}$ (Fig. 4a, b). Furthermore, no toxic effect was observed when final vaccine product was analyzed (Fig. 6). Since batches of bulk antigen are produced at high-quality standards, it is not surprising that the anti- $T$ IgG responses of two different batches were comparable and showed tight correlation on individual donor level (Fig. 4d, e), thus demonstrating consistency in the immune stimulatory effect.

Interestingly, we observed differences in the strength of response when PBMC were stimulated with $\Pi$ from different manufacturers (Fig. 4f) although $\Pi$ bulks might be expected to contain identical epitopes. This finding might, thus, be attributable to the different adjuvants used for $\Pi$ adsorption (e.g., aluminum phosphate versus aluminum hydroxide) or the respective amount of adjuvant. Thus, the assay detects differences in adjuvant and its complexion with the antigen. However, it cannot be excluded that the results were influenced by the donor history of vaccine products used for previous booster vaccinations. Nevertheless, anti-TT lgG levels obtained from individual donor cells correlated well (Fig. 4g), reflecting consistency and suitability for comparative analysis of antigens.

Notably, the experiments with heat-treated $\Pi T$ samples did not show statistically significant differences compared with the nonaltered $\Pi$ (Fig. 5). However, we have no evidence that heat exposure induced alterations affecting the B-cell epitopes. Thus, the current assay design allows conclusions on the immunogenicity of $\Pi$ antigen but cannot distinguish alternated $\Pi$ if immunodominant epitopes are preserved.

Even though vaccines containing $\Pi$ have been used for $>90$ years $^{45}$ and are produced under GMP conditions, ensuring consistent quality of $\Pi$ vaccines requires vaccine batches to be tested before release. To date, these tests include in vivo potency assays performed as either challenge or immunogenicity studies. Altogether, the method evaluated in this study provides an easy in vitro tool to monitor presence and immunogenic potential of vaccine antigen based on eliciting a recall response from preformed antigen-specific memory B cells. Our results demonstrate the feasibility and specificity of an in vitro assay for functional testing of $\Pi$ in bulk antigen and final vaccine product. Importantly, in contrast to current animal testing, this assay assesses antigen immunogenicity in the context of the human immune response. Furthermore, this response was independent of the presence of adjuvants, other antigens or excipients contained in the final vaccine formulation (Fig. 6). Although the assay in its current form is not suitable for quantification of $\Pi \pi$ antigen content, functional $\Pi$ integrity is relevant and can complement biochemical assays in replacing in vivo potency testing. Prequalification of donor cells represents an important asset for reproducibility and reliability of the assay. Follow-up studies focused on reproducibility or sensitivity of the assay in the presence of $\Pi \pi$ antigen with altered epitopes are needed to further characterize the assay and its limitations. Final method validation further requires a parallel study with the established methodology.

\section{METHODS}

\section{Cell isolation and cryopreservation}

Peripheral blood mononuclear cells (PBMC) were isolated from buffy coats from healthy donors obtained from German Red Cross South transfusion center (Frankfurt am Main, Germany) or from healthy volunteers before and 7-26 days after booster DTaP vaccination, which occurred 5-16 years after their previous vaccination. Table 2 summarizes the donor characteristics. The use of buffy coats and the blood collection from healthy donors before and after vaccination were approved by the ethics committee of the University of Frankfurt, approvals \#154/15 and \#58/16, respectively. Blood of fresh blood donors' was collected after informed consent was signed. All subjects gave their informed consent for inclusion before they participated in the study and the study was conducted in accordance with the Declaration of Helsinki.

PBMC were isolated by Pancoll gradient centrifugation (PAN-Biotech, Germany). Before cryopreservation, isolated PBMC were centrifuged and resuspended in fetal calf serum (FCS) to the concentration $30 \mathrm{Mio} / \mathrm{ml}$. Aliquots à $15 \mathrm{Mio}(500 \mu \mathrm{l}$ of the cell suspension) per freezing vial (CryovialsCryo.S; Greiner Bio-One, Austria) from each donor were prepared. Shortly before vial would be closed, mixed by inverting and placed into slowly cooling container (CoolCell ${ }^{\circledR}$ LX, Biocision, USA) additional $500 \mu \mathrm{l}$ of freezing media (20\% FCS (Sigma-Aldrich Chemie GmbH, Germany), 60\% RPMI (RPMI 1640; Gibco, Germany) and 20\% DMSO (Dimethyl sulfoxide; Sigma-Aldrich Chemie GmbH, Germany)) were added to the cell aliquot in each vial. Freezing container with vials was immediately placed into $-80^{\circ} \mathrm{C}$ freezer.

\section{Thawing procedure}

Required number of frozen vials of each donor was processed proportionally to the number of vials according to the following protocol. One vial containing $1 \mathrm{ml}$ of cell suspension was placed into $37^{\circ} \mathrm{C}$ water bath for $1 \mathrm{~min}$. The cell suspension was transferred into $1 \mathrm{ml}$ of prewarmed $\left(37^{\circ} \mathrm{C}\right)$ thawing medium prepared as $50 \%$ FCS, $50 \%$ HEK medium $(90 \%$ 


\begin{tabular}{|c|c|c|c|c|c|c|c|c|}
\hline Donor \#1 & M & 26 & 13 & 26 & 1,3 & 9,9 & 10,015 & 10,323 \\
\hline Donor \#2 & $\mathrm{F}$ & 34 & 9 & 26 & 0,6 & 12,0 & 12,928 & 16,037 \\
\hline Donor \#5 & M & 33 & 6 & 15 & 1,4 & 3,6 & 17,079 & 18,386 \\
\hline Donor \#6 & $F$ & 55 & 7 & 18 & 6,6 & 7,1 & 7914 & 7242 \\
\hline Donor \#7 & M & 47 & 5 & 20 & 1,2 & 3,9 & 13,996 & 13,577 \\
\hline Donor \#8 & $\mathrm{F}$ & 26 & 8 & 14 & 0,9 & 9,9 & 13,834 & 12,377 \\
\hline Donor \#9 & $\mathrm{F}$ & 25 & 9 & 20 & n.a. & 8,4 & n.a. & 11,945 \\
\hline
\end{tabular}

RPMI medium, 10\% FCS, 1\% L-glutamine (200 mM) (Biochrom, Germany), $1 \%$ penicillin/streptomycin $(10,000 \mathrm{U} / \mathrm{ml})($ Merck, Germany)) and $180 \mathrm{U} / \mathrm{ml}$ of DNAse I (Roche, Switzerland). Followed by immediate addition of $1 \mathrm{ml}$ prewarmed $\left(37^{\circ} \mathrm{C}\right) \mathrm{HEK}$ media. Cell suspension was placed for 1 hour in and $37^{\circ} \mathrm{C}$ incubator. Afterwards, the cell suspension was centrifuged $(360 \times 9,6 \mathrm{~min}, \mathrm{RT})$ and the supernatant was discarded. Cells were resuspended in $1 \mathrm{ml}$ HEK media and counted using trypan blue (ApplichemPanreac, Germany) and Neubauer chamber.

\section{Cell culture}

PBMC were seeded into 48-well plate (Greiner Bio-One, Germany) $2 \times 10^{6}$ per well. Cells in all conditions were stimulated with full-length PTOmodified CpG 2006 (5'-tcgtcgttttgtcgttttgtcgtt-3') (EurofinsGenomics, Germany) at a final concentration of $0.002 \mu \mathrm{M}$. $\Pi$ adsorbed to alum adjuvant from manufacturer \#1 (lot\# A and B) and manufacturer \#2 (lot\# C) were used at a concentration of $0.0025 \mathrm{Lf} / \mathrm{ml}$, if not stated otherwise. Alumadsorbed DT bulk antigen provided by manufacturer \#1 was used at a final concentration of $0.0025 \mathrm{Lf} / \mathrm{ml}$ (final concentration of $\mathrm{AlPO}_{4} 0.052 \mu \mathrm{g} / \mathrm{ml}$, corresponding to aluminum $\mathrm{Al}^{3+}$ concentration $0.011 \mu \mathrm{g} / \mathrm{ml}$ ). AlPO obtained from manufacturer \#1 was applied as control at a final concentration of $0.058 \mu \mathrm{g} / \mathrm{ml} \mathrm{AlPO}{ }_{4}$ (corresponding to aluminum $\mathrm{Al}^{3+}$ concentration $0.013 \mu \mathrm{g} / \mathrm{ml}$ ), which is equivalent to the amount in Alumadsorbed $\Pi$ conditions $(0.0025 \mathrm{Lf} / \mathrm{ml})$. In the experiment, where $\Pi$ adsorbed from two manufacturers was compared, $\Pi \pi$ adsorbed from manufacturer \#2 was used at a concentration of $0.0025 \mathrm{Lf} / \mathrm{ml}$, the adsorbent $\mathrm{Al}(\mathrm{OH})_{3}$ in final concentration of $0.26 \mu \mathrm{g} / \mathrm{ml}$ (corresponding to aluminum $\mathrm{Al}^{3+}$ concentration $0.13 \mu \mathrm{g} / \mathrm{ml}$ ). DTaP and a DaP drop-out sample lacking $\Pi T$ were provided by manufacturer $\# 1$ and used for stimulation at a final concentration of $0.0025 \mathrm{Lf} / \mathrm{ml}$ of $\pi$ (4000-fold dilution). Wherever possible, each condition was performed in six or eight technical replicates. The final volume of the stimulated cell suspension was $1 \mathrm{ml}$ per well in a 48 -well plate. Cells were subsequently incubated in $37^{\circ} \mathrm{C}$, $5 \% \mathrm{CO}_{2}$ for 5 days.

\section{ELISpot}

MultiScreen HTS IP Durapore PVDF ELISpot plates (Merck, Germany) were coated with $10 \mathrm{Lf} / \mathrm{ml} \Pi$ (AJ vaccines, Denmark) or with $6.25 \mathrm{ng} / \mathrm{ml}$ antihuman IgG (clone MT91/145; Mabtech, Sweeden) in PBS overnight at $4{ }^{\circ} \mathrm{C}$. Before cell seeding, the ELISpot plates were washed three times with PBS and block with HEK media for at least $30 \mathrm{~min}$ at the room temperature (RT). Cells after 5 days of incubation in 48-well plate were centrifuged $(360 \times g$, $6 \mathrm{~min}, 20^{\circ} \mathrm{C}$ ) and cell were washed carefully twice with $1 \mathrm{ml}$ of HEK media. After the supernatants were discarded, the cells in each well were resuspended in $400 \mu \mathrm{l}$ of HEK media. In all, $200 \mu \mathrm{l}$ of the cell suspension of single well was transferred in single $\Pi \mathrm{T}$ coated ELISpot well. For detection of total $\mathrm{lgG}$ secretion $-190 \mu \mathrm{l}$ from the other portion of stimulated PBMC was discarded and $400 \mu \mathrm{l}$ of HEK media was added. From this 40 times diluted cell suspension (to prevent too high number of total IgG spots per
ELISpot well), $200 \mu \mathrm{l}$ of cells were seeded on anti-human IgG coated ELISpot plate. Cells were placed in $37^{\circ} \mathrm{C}$ incubator with $5 \% \mathrm{CO}_{2}$ for 4 hours. The cells were subsequently discarded and plate was washed three times with PBS. Biotinylated anti-lgG detection mAbs MT78/145 clone (Mabtech, Sweden) at a concentration of $0.001 \mathrm{mg} / \mathrm{ml}$ in PBS supplemented with $10 \%$ FCS were added to the wells and incubated for 2 hours at RT. The plates were washed three times with PBS with 0.05\% Tween 20 (Sigma-Aldrich, Germany) before streptavidin conjugated with Alkaline-phosphatase (Becton Dickinson, USA) diluted 1:1000 in PBS with 10\% FCS was added and incubated for 1 hour at RT. Plates were washed three times with PBS with $0.05 \%$ Tween 20 and three times with PBS. AP-conjugate Substrate kit (BioRad, Germany) was added to the wells for 2-5 min. The reaction was stopped by rinsing the plates with tap water. The plates were dried overnight in dark. Evaluation of plates was done with iSpot ELISpot reader (AID, Germany) with EliSpot Reader v.7.0 (AID, Germany) within 7 days from development.

Production of antibodies is measured as enzymatic activity, which facilitates quantification and directly correlates with the number, intensity and size of the spots within the well. A threshold enzymatic activity of $\geq 200$ was setup as a limit of "reactivity" of the PBMC in a well. This threshold represents minimal limit of eye-visible reaction in a well. Enzymatic activity of 200 is represented in the graphs with a dotted line where applicable.

"Reactive donor cells" were defined by the following criteria: (1) if an enzymatic activity was $\geq 200$ in at least one of six replicate wells stimulated with CpG and $\Pi$ and (2) if the highest value of the enzymatic activity from the wells treated with $\mathrm{CpG}$ and $\Pi \mathrm{T}$ was higher than that obtained in all wells that were stimulated with CpG only.

\section{Enumeration of TT-specific memory B cells by ELISpot}

PBMC were plated in 48-well plate at a concentration of $2 \times 10^{6}$ cells per well in $1 \mathrm{ml}$ of HEK media supplemented with R848 $(1 \mu \mathrm{g} / \mathrm{ml})$ (Invivogen, USA) and $10 \mathrm{ng} / \mathrm{ml} \mathrm{IL-2} \mathrm{(Miltenyi,} \mathrm{Germany)} \mathrm{and} \mathrm{cultured} \mathrm{in} 37^{\circ} \mathrm{C}$ with $5 \%$ $\mathrm{CO}_{2}$. On day 5 PBMC were washed and seeded in twofold serial dilutions in duplicates $\left(0.5,0.25\right.$, and $\left.0.125 \times 10^{6}\right)$ and incubated for 4 hours on ELISpot plates coated with $\Pi$ (AJ vaccines, Denmark) ${ }^{38}$. The coating and developing procedures were performed as described above. Frequency of $T$-specific memory B cells was determined per $1 \times 10^{6}$ of PBMC.

\section{FACS staining}

For B-cell count and B-cell subpopulations determination, 200,000 PBMC were transferred into $96 \mathrm{U}$-well plate (Greiner Bio-One, Germany). After PBS was added up to volume of $200 \mu \mathrm{l}$, the plate was centrifuged $(360 \times \mathrm{g}$, $6 \mathrm{~min}, \mathrm{RT}$ ). Cells were stained with $50 \mu \mathrm{l}$ of mixture of anti-human CD19-PC7 (clone J3-119; Beckman Coulter, USA), anti-human CD27-BV421 (clone MT271; Becton Dickinson, USA), anti-human IgM-PerCP Cy5.5 (clone MHM88; BioLegend, USA) and PBS with $0.5 \%$ FCS for $30 \mathrm{~min}, 4^{\circ} \mathrm{C}$, dark. Afterwards $150 \mu \mathrm{l}$ PBS with $0.5 \%$ FCS was added and the samples were 
centrifuged $(360 ; \times g, 6$ min, RT), supernatant discarded. The cells were resuspend in $100 \mu \mathrm{l}$ of PBS, followed by adding $100 \mu \mathrm{l}$ of $4 \%$ PFA (paraformaldehyde) (Sigma-Aldrich Chemie $\mathrm{GmbH}$, Germany) and the suspension was well mixed. The samples were kept in fridge $\left(4^{\circ} \mathrm{C}\right)$ overnight. Next day, the samples were washed before the measurement and cells were resuspended in PBS with $0.5 \%$ FCS. Samples were measured on a BD LSRII SORP flow cytometer with BD FACS Diva software version 8.0.1 (Becton Dickinson, USA) and analyzed with Kaluza Analysis Software (Beckman Coulter, USA). The gating strategy is shown in Supplementary Fig. 8.

\section{Flow cytometric enumeration of TT-specific memory B cells}

Before staining, untouched $B$ cells were enriched from PBMC using the EasySep human B-cell enrichment kit (StemCell Technologies, Canada). TTspecific B cells in buffy coat PBMC were then characterized with an antibody panel consisting of anti-human CD19-PC7 (clone J3-119; Beckman Coulter, USA), anti-human CD27-BV711 (clone O323; BioLegend, USA), antihuman IgM-BV605 (clone MHM-88; BioLegend, USA), anti-human IgA (clone REA1014; Miltenyi, Germany) and with $\Pi$ purchased from AJ vaccines, Denmark, biotinylated with EZ-Link Sulfo-NHS-LC-Biotin (Thermo Fisher Scientific, UK) and fluorescently labeled with streptavidin-BV421 (BioLegend, USA). Samples were measured on a FACS Aria $^{\mathrm{TM}}$ Fusion (Beckman Coulter, USA). The gating strategy is depicted in Supplementary Fig. 2c.

\section{ELISA}

Levels of anti-T IgG antibodies in plasma of were evaluated by human anti-TT IgG EIA Kit (The Binding Site, United Kingdom) according to the protocol provided by the manufacturer.

\section{Statistical analysis}

Statistical analysis of results was performed using GraphPad Prism 8.4.2 (GraphPad Software LLC, USA). Data were analyzed using two-tailed Wilcoxon matched-pairs signed rank test, two-tailed Mann-Whitney test and Spearman correlation. $P$ values are depicted in the respective graphs, ns non-significant.

\section{Reporting summary}

Further information on research design is available in the Nature Research Reporting Summary linked to this article.

\section{DATA AVAILABILITY}

All data from this study are available from the corresponding author upon reasonable request.

Received: 25 November 2020; Accepted: 24 May 2021;

Published online: 23 June 2021

\section{REFERENCES}

1. Di Tommaso, A. et al. Formaldehyde treatment of proteins can constrain presentation to T cells by limiting antigen processing. Infect. Immun. 62, 1830-1834 (1994).

2. Möller, J., Kraner, M. E. \& Burkovski, A. More than a toxin: protein inventory of clostridium tetani toxoid vaccines. Proteomes 7; https://doi.org/10.3390/ proteomes7020015 (2019).

3. Bödeker, B., Remschmidt, C., Müters, S. \& Wichmann, O. Impfquoten unter Erwachsenen in Deutschland für die Impfungen gegen saisonale Influenza, Tetanus und Pertussis. Bundesgesundheitsblatt Gesundheitsforschung Gesundheitsschutz 58, 174-181 (2015).

4. Rappuoli, R., Pizza, M., Douce, G. \& Dougan, G. New vaccines against bacterial toxins. Adv. Exp. Med. Biol. 397, 55-60 (1996).

5. Weinberger, B. Adult vaccination against tetanus and diphtheria: the European perspective. Clin. Exp. Immunol. 187, 93-99 (2017).

6. World Health Organization. The immunological basis for immunization series: module 3: tetanus (World Health Organization, 2018).

7. Poethko-Müller, C. \& Schmitz, R. Impfstatus von Erwachsenen in Deutschland: Ergebnisse der Studie zur Gesundheit Erwachsener in Deutschland (DEGS1).
Bundesgesundheitsblatt, Gesundheitsforschung, Gesundheitsschutz 56, 845-857 (2013).

8. Hammarlund, E. et al. Plasma cell survival in the absence of B cell memory. Nat. Commun. 8, 1781 (2017).

9. Embree, J., Law, B., Voloshen, T. \& Tomovici, A. Immunogenicity, safety, and antibody persistence at 3,5 , and 10 years postvaccination in adolescents randomized to booster immunization with a combined tetanus, diphtheria, 5component acellular pertussis, and inactivated poliomyelitis vaccine administered with a hepatitis B virus vaccine concurrently or 1 month apart. Clin. Vaccine Immunol. 22, 282-290 (2015).

10. Plotkin, S. A., Orenstein, W. A. \& Offit, P. A. Vaccines. 6th edn (Elsevier/Saunders, 2013).

11. World Health Organization. Tetanus Vaccines: WHO Position Paper - February 2017. Wkly. Epidemiol. Rec. 92, 53-76 (2017).

12. Bernasconi, N. L., Traggiai, E. \& Lanzavecchia, A. Maintenance of serological memory by polyclonal activation of human memory B cells. Science 298, 2199-2202 (2002).

13. McHeyzer-Williams, M. G. \& Ahmed, R. B cell memory and the long-lived plasma cell. Curr. Opin. Immunol. 11, 172-179 (1999).

14. Sallusto, F., Lanzavecchia, A., Araki, K. \& Ahmed, R. From vaccines to memory and back. Immunity 33, 451-463 (2010).

15. EDQM. Chapter 2.7.8: Assay of tetanus vaccine (adsorbed); In: European Pharmacopoeia 6 (Directorate for the Quality of Medicines \& HealthCare of the Council of Europe (EDQM), Strasbourg, 2008).

16. World Health Organization. Recommendations for diphtheria, tetanus, pertussis and combined vaccines (Amendments 2003). Annex 5. WHO Technical Report Series, No. 927 (2005).

17. Council of Europe. ETS No.123: European Convention for the Protection of Vertebrate Animals used for Experimental and Other Scientific Purposes, 1-11 (Strasbourg, 1986).

18. The European Parliament and the Council of the European Union. DIRECTIVE 2010/63/EU on the protection of animals used for scientific purposes. Official Journal of the European Union, 33-79 (2010).

19. EDQM. Chapter 5.2.14: Substitution of in vivo methods by in vitro methods for the quality control of vaccines. In: European Pharmacopoeia 10.0 (Directorate for the Quality of Medicines \& HealthCare of the Council of Europe (EDQM), Strasbourg, 2018).

20. Metz, B. et al. Physicochemical and immunochemical assays for monitoring consistent production of tetanus toxoid. Biologicals 41, 231-237 (2013).

21. Coombes, L., Tierney, R., Rigsby, P., Sesardic, D. \& Stickings, P. In vitro antigen ELISA for quality control of tetanus vaccines. Biologicals 40, 466-472 (2012).

22. Michiels, T. J. M. et al. Degradomics-based analysis of tetanus toxoids as a quality control assay. Vaccines 8; https://doi.org/10.3390/vaccines 8040712 (2020).

23. Behrensdorf-Nicol, H. A., Weisser, K. \& Krämer, B. "BINACLE" assay for in vitro detection of active tetanus neurotoxin in toxoids. ALTEX 32, 137-142 (2015).

24. Jahnmatz, M. et al. Optimization of a human IgG B-cell ELISpot assay for the analysis of vaccine-induced B-cell responses. J. Immunol. Methods 391, 50-59 (2013).

25. Kyu, S. Y. et al. Frequencies of human influenza-specific antibody secreting cells or plasmablasts post vaccination from fresh and frozen peripheral blood mononuclear cells. J. Immunol. Methods 340, 42-47 (2009).

26. Saletti, G., Çuburu, N., Yang, J. S., Dey, A. \& Czerkinsky, C. Enzyme-linked immunospot assays for direct ex vivo measurement of vaccine-induced human humoral immune responses in blood. Nat. Protoc. 8, 1073-1087 (2013).

27. Crotty, S., Aubert, R. D., Glidewell, J. \& Ahmed, R. Tracking human antigen-specific memory B cells: a sensitive and generalized ELISPOT system. J. Immunol. Methods 286, 111-122 (2004).

28. Weiss, G. E. et al. High efficiency human memory B cell assay and its application to studying Plasmodium falciparum-specific memory B cells in natural infections. J. Immunol. Methods 375, 68-74 (2012).

29. Bernasconi, N. L., Onai, N. \& Lanzavecchia, A. A role for Toll-like receptors in acquired immunity: up-regulation of TLR9 by BCR triggering in naive $B$ cells and constitutive expression in memory B cells. Blood 101, 4500-4504 (2003).

30. Jung, J. et al. Distinct response of human $B$ cell subpopulations in recognition of an innate immune signal, CpG DNA. Journal of immunology (Baltimore, Md.: 1950) 169, 2368-2373; (2002).

31. Tangye, S. G. \& Tarlinton, D. M. Memory B cells: effectors of long-lived immune responses. Eur. J. Immunol. 39, 2065-2075 (2009).

32. Palkola, N. V. et al. Pathogen-specific circulating plasmablasts in patients with pneumonia. PloS one 7, e34334 (2012).

33. Tuaillon, E. et al. Detection of memory B lymphocytes specific to hepatitis B virus (HBV) surface antigen (HBsAg) from HBsAg-vaccinated or HBV-immunized subjects by ELISPOT assay. J. Immunol. Methods 315, 144-152 (2006). 
34. Latner, D. R. et al. Enzyme-linked immunospot assay detection of mumps-specific antibody-secreting B cells as an alternative method of laboratory diagnosis. Clin. Vaccine Immunol 18, 35-42 (2011).

35. Sullivan, N. L. et al. Breadth and functionality of varicella-zoster virus glycoprotein-specific antibodies identified after zostavax vaccination in humans. J. Virol. 92 https://doi.org/10.1128/JVI.00269-18 (2018).

36. Buisman, A. M., Rond, C. G. H., de, Oztürk, K., Hulscher, H. Iten \& van Binnendijk, R. $\mathrm{S}$. Long-term presence of memory B-cells specific for different vaccine components. Vaccine 28, 179-186 (2009).

37. Giesecke, C. et al. Tissue distribution and dependence of responsiveness of human antigen-specific memory B cells. J. Immunol. 192, 3091-3100 (2014).

38. Jahnmatz, P. et al. Multiplex analysis of antigen-specific memory B cells in humans using reversed B-cell FluoroSpot. J. Immunol. Methods 478, 112715 (2020).

39. Franz, B., May, K. F., Dranoff, G. \& Wucherpfennig, K. Ex vivo characterization and isolation of rare memory $B$ cells with antigen tetramers. Blood 118, 348-357 (2011).

40. Lanzavecchia, A. et al. Understanding and making use of human memory B cells. Immunol. Rev. 211, 303-309 (2006).

41. Amanna, I. J., Carlson, N. E. \& Slifka, M. K. Duration of humoral immunity to common viral and vaccine antigens. N. Engl. J. Med. 357, 1903-1915 (2007).

42. Kouskoff, V. et al. Antigens varying in affinity for the B cell receptor induce differential B lymphocyte responses. J. Exp. Med. 188, 1453-1464 (1998).

43. Ghraichy, M. et al. Maturation of the human B-cell receptor repertoire with age. Front. Immunol. 11, 1734 (2019)

44. IJspeert, $\mathrm{H}$. et al. Evaluation of the antigen-experienced B-cell receptor repertoire in healthy children and adults. Front. Immunol. 7, 410 (2016).

45. Plotkin, S. History of vaccination. Proc. Natl. Acad. Sci. USA 111, 12283-12287 (2014).

\section{ACKNOWLEDGEMENTS}

This work was funded by the EU/EFPIA Innovative Medicines Initiative 2 Joint Undertaking (IMI2 JU) VAC2VAC project [grant agreement No. 115924]. TT and DT vaccine antigens, alum adjuvant, bulk antigen and vaccine samples including dropout samples were provided by Sanofi Pasteur Ltd. and GlaxoSmithKline within the VAC2VAC project. We thank Volker Öppling, Langen; Nolwenn Nougarede, Sanofi and Thierry Laurent, Charline Hoebreck and Shahjahan Shaid, GSK for critical reading of the manuscript. I.B.D. received further funding from the German Ministry of Education and Research (BMBF) [grant 031L0147]. The content of this article reflects the authors' view and the IMI2 JU is not responsible for any use that may be made of the information contained therein.

\section{AUTHOR CONTRIBUTIONS}

O.T. and I.B.D. conceived the study, designed the experiments. and wrote the manuscript. O.T., D.K., and L.M. performed and analyzed the experiments. D.K. and L. M. helped to develop protocols.

\section{FUNDING}

Open Access funding enabled and organized by Projekt DEAL.

\section{COMPETING INTERESTS}

The authors declare the following competing interests: $\Pi$ and DT vaccine antigens, alum adjuvant, bulk antigen, and vaccine samples including drop-out samples were provided by Sanofi Pasteur Ltd. and GlaxoSmithKline within the IMI2 VAC2VAC project.

\section{ADDITIONAL INFORMATION}

Supplementary information The online version contains supplementary material available at https://doi.org/10.1038/s41541-021-00344-1.

Correspondence and requests for materials should be addressed to I.B-D.

Reprints and permission information is available at http://www.nature.com/ reprints

Publisher's note Springer Nature remains neutral with regard to jurisdictional claims in published maps and institutional affiliations.

(c) Open Access This article is licensed under a Creative Commons Attribution 4.0 International License, which permits use, sharing, adaptation, distribution and reproduction in any medium or format, as long as you give appropriate credit to the original author(s) and the source, provide a link to the Creative Commons license, and indicate if changes were made. The images or other third party material in this article are included in the article's Creative Commons license, unless indicated otherwise in a credit line to the material. If material is not included in the article's Creative Commons license and your intended use is not permitted by statutory regulation or exceeds the permitted use, you will need to obtain permission directly from the copyright holder. To view a copy of this license, visit http://creativecommons. org/licenses/by/4.0/.

(c) The Author(s) 2021 